\title{
Conversando Sobre a Morte e o Morrer na Área da Deficiência
}

Talking about deaht and the act of dying in the area of deficiency
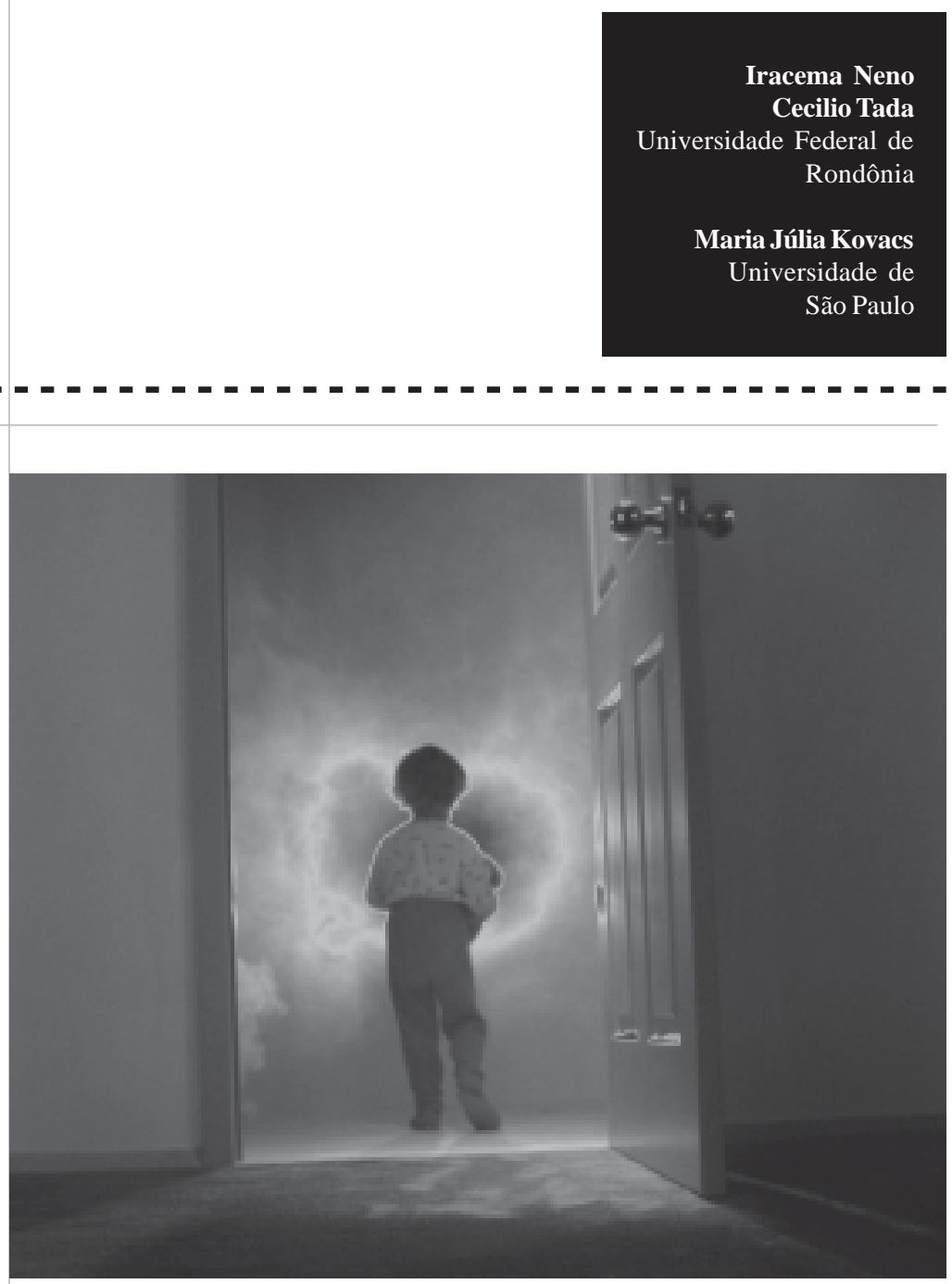


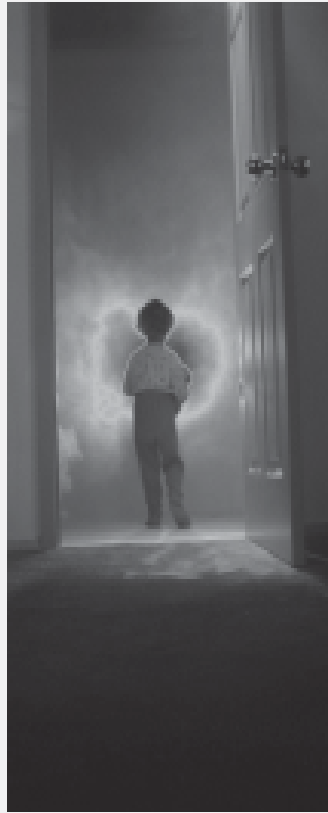

Resumo:Nesta pesquisa, buscamos conhecer como a morte e o morrer são vivenciados em uma instituição que atende pessoas com paralisia cerebral, tendo em vista o falecimento de três crianças ali atendidas. Realizamos entrevistas semi-estruturadas, gravadas em áudio com os profissionais, procurando compreender como lidam com a morte, como elaboram o luto e como informaram aos seus pacientes sobre o falecimento dos colegas.

Palavras- chave: paralisia cerebral, morte, morrer, luto.

Abstract: In this study we try to understand how death and dying are experienced in an institution that assists people with cerebral palsy, since three children who were assisted there died. We did semi-structured recorded interviews with professionals, seeking to understand how they deal with death, how they elaborate the losses and how they inform their patients about the death of a close person.

Key words: cerebral palsy, death, act of dying, mourning.

Em geral, os estudos sobre a morte e o morrer têm enfocado a reação de profissionais de saúde, principalmente médicos, frente à morte do paciente terminal, sendo uma das grandes pioneiras a psiquiatra Elisabeth KüblerRoss, que chamou a atenção, na década de sessenta, para a necessidade de estudarmos e falarmos sobre a temática da morte, em busca de um atendimento mais humanizado nos hospitais.

Para Áries (1990), é a partir do século XX que a civilização ocidental passa a esconder a morte, evitando falar sobre ela, numa tentativa de proteger a vida. Como conseqüência, a atitude mais adequada para lidar com a morte de um ente querido seria fingir que nada aconteceu, que nada mudou, contribuindo, dessa forma, para o medo diante da morte, do desconhecido.

Áries denomina morte invertida essa representação da morte, por ocorrer uma inversão nas características da morte, nas quais ela necessita passar despercebida, não sendo mais considerada um fenômeno natural do ser vivo, e sim, um fracasso. Tal representação leva a uma negação, a uma não aceitação da morte e a uma falsa sensação de que viveremos eternamente, aumentando, assim, o medo diante da morte.

Para Cassorla (1998), a negação da morte é percebida quando ficamos sem saber como agir diante de um conhecido que perdeu um ente querido, não lhe dando os pêsames, evitando ir ao velório ou contando piadas no velório. Atitudes como essas parecem colaborar para a percepção errônea de que tudo está bem, de que nada aconteceu, por não querermos vivenciar o sentimento de dor e de sofrimento pela perda.

Parece que não queremos entrar em contato com a nossa própria finitude e buscamos logo retomar as nossas atividades normais. A vida, de acordo com Cassorla, é o maior bem que temos, mas, para vivermos bem, temos que aceitar que a morte faz parte da vida e que todos morreremos algum dia.

Negar a morte é não querer entrar em contato com as experiências que nos causam 
sofrimento, permitindo, assim, segundo Kovács (2002), fantasiar a ilusão da imortalidade, dando a idéia de força e de controle sobre o medo da morte.

O medo da morte "é a resposta psicológica mais comum diante da morte", sendo, portanto, um sentimento universal e vital, pois ajuda o indivíduo a superar os instintos destrutivos (Kovács, 1992, p. 16).

O medo se torna preocupante quando doentio, podendo contribuir para um enlutamento inadequado, o que pode levar o enlutado a tornar-se mais susceptível a doenças, à melancolia ou a outros processos substitutivos (Cassorla, 1998; Kovács, 2002).

\section{O luto}

Podemos dizer que o luto seria o processo de elaboração do sentimento de pesar devido à perda de uma pessoa querida, que envolve, portanto, muita tristeza. Para Bowlby (1985), são quatro as fases do luto: a fase de entorpecimento, na qual a pessoa tem, como reação imediata, o choque, sendo incapaz de aceitar a notícia da perda; a fase de anseio e busca pela pessoa perdida, quando o enlutado vivencia sentimentos da presença concreta do ente falecido, e de raiva, por não conseguir restabelecer o elo partido; a fase de desorganização e de desespero, em decorrência de o enlutado não poder reviver o morto, o que pode levar a pessoa a tornarse deprimida ou apática, e a fase de maior ou menor grau de reorganização, quando ocorre a aceitação gradual da perda, com a percepção de que é necessário reconstruir a sua vida. Para que o enlutado aceite melhor essa perda, Bowlby postula ser necessário que as pessoas que lidam diretamente com ele tolerem o seu abatimento e o seu luto, proporcionando-lhe uma atmosfera acolhedora, para que ele possa elaborar melhor essa perda e reestruturar a sua vida.
O processo de luto só estará finalizado, de acordo com Kovács (1992, p. 50), quando existir “a presença da pessoa perdida internamente em paz”, havendo "um espaço disponível para outras relações”, sendo, portanto, necessário um tempo para vivenciar o luto, e não para negá-lo.

A necessidade de o enlutado vivenciar o seu sentimento de perda é importante para que ele possa externalizar a sua dor, o que proporciona as condições necessárias para uma boa elaboração do luto e possibilita a retomada de sua vida, ao lado das recordações da pessoa perdida, que incluem carinho e paz (Cassorla, 1998).

Fatores como o tipo de morte (se inesperada ou não), o relacionamento do enlutado com o falecido, as condições de vida do enlutado, sua idade e fatores socio-econômicos também irão afetar o processo de luto (Bromberg, 1996; Kovács, 1992).

De acordo com Cassorla (1998), o problema do luto mal-elaborado estaria no risco de ele se alastrar por várias gerações de uma determinada família, tal qual uma doença contagiosa, o que pode desencadear o aparecimento de doenças, devido à baixa resistência do sistema imunológico, como também pode vir a colaborar para o desenvolvimento de comportamentos antisociais, como a criminalidade, o uso de drogas e o suicídio.

O luto mal-elaborado também se encontra presente entre os profissionais de saúde que lidam diretamente com pacientes terminais, que tendem a não expressar seus sentimentos de tristeza, de dor e de pesar por meio do abafamento dessas sensações, em busca da eficácia de suas atividades laborais. Ao camuflarem os seus sentimentos de pesar, no entanto, a relação com seus pacientes pode ser comprometida pelo fato de eles se apresentarem formais e impessoais (Kovács, 1998; 2002; Kübler-Ross, 1996; 1998). 
Stedefor (1986) analisa que alguns médicos se apresentam mais reservados em sua relação com seus pacientes, principalmente com os pacientes terminais, por terem a consciência dos riscos de virem a sofrer emocionalmente quando estes falecerem, utilizando, portanto, mecanismos de defesa, como a racionalização e a intelectualização, numa tentativa de evitar o sofrimento da perda ou a vitória da doença em detrimento da sua ação profissional.

\section{A criança e a morte}

A criança está sempre atenta a tudo o que acontece ao seu redor. Os adultos, geralmente, tendem a esconder a morte da criança, por acreditarem que ela ainda é muito pequena para vivenciar o sofrimento da perda. Mas, como afirma Kovács (1992), a morte faz parte do desenvolvimento humano desde a mais tenra idade, quando a criança vivencia situações de perda, como a morte de seu bichinho de estimação, a quebra ou perda de seu brinquedo preferido, entre outras.

Tais perdas vão ajudando a criança a elaborar uma representação da morte que vai evoluindo gradualmente, em concomitância com o seu desenvolvimento cognitivo. Sendo assim, devemos comunicar à criança o falecimento de um ente querido, fazendo-se necessário conhecer a concepção que ela tem sobre a morte, pois assim teremos as "linhas-mestras daquilo o que ela é capaz de compreender nas diferentes etapas do desenvolvimento" (Torres, W.; Guedes; Torres, R.; Ebert, 1998, p. 132). A criança, segundo Kovács (1992, p. 4), “não expressará a sua dor se não souber que aconteceu uma morte, entretanto", ela "percebe que algo aconteceu, pois todos estão agindo de uma forma diferente." Nesse sentido, a autora destaca, em sua tese de livre-docência sobre a educação para a morte, defendida em 2002, que a conduta mais valiosa ao se comunicar a morte de um ente querido à criança seria o da escuta, ou seja, estar atenta às perguntas que a criança fizer e detectar os seus sentimentos, compartilhando e trabalhando, dessa forma, a dor pela perda.

O não esclarecimento à criança do falecimento de um ente querido pode levá-la a vivenciar sentimentos de culpa em decorrência de seu pensamento mágico e de sua onipotência, características essas comuns no desenvolvimento infantil, por, talvez, ter desejado, em algum momento, essa morte ou por ter brigado com a pessoa. Tal sentimento pode ser minimizado ou até evitado, se for comunicada à criança a causa real dessa morte (Kovács, 1992).

Outra característica comum do pensamento infantil é com relação à reversibilidade, tão presente nos desenhos animados, nos quais podemos observar, por exemplo, um piano caindo em cima do personagem Tom, do seriado Tom e Jerry e, logo em seguida, seu surgimento, como se nada tivesse ocorrido, vivo, sem machucados, em nova perseguição ao Jerry! Essa mensagem é assimilada pela criança, sendo necessário o diálogo com o adulto para que ela possa perceber que, quando um amiguinho morre, ele não retorna à vida, como acontece nos desenhos infantis. Quando analisamos os estudos sobre a morte na área da deficiência, percebemos que o centro das discussões tem sido a morte simbólica do filho ou paciente perfeito, que nasce ou adquire qualquer tipo de deficiência, seja mental, física ou sensorial. Nesse sentido, as questões abordadas referem-se aos cinco estágios de enfrentamento de perdas significativas proposta por Kübler-Ross (1996), a saber: negação, raiva, barganha, depressão e aceitação.

A criança com deficiência também sofre perdas de pessoas significativas em sua vida. Refletindo sobre essas questões, acreditamos ser de grande relevância compreender como os profissionais que atuam diretamente com aquelas que apresentam diagnóstico de paralisia cerebral, com ou sem deficiência
... a morte faz parte do desenvolvimento humano desde a mais tenra idade, quando a criança vivencia situações de perda, como a morte de seu bichinho de estimação, a quebra ou perda de seu brinquedo preferido, entre outras.

Kovács 
mental, lidam com a temática da morte e do morrer, considerando que a instituição pesquisada tenha vivenciado a perda de três crianças por ela atendida. Nesse sentido, temos, como perguntas norteadoras: como essas perdas foram repassadas para os demais pacientes? Como a equipe foi preparada para lidar com a morte? Como os profissionais vivenciaram o luto por essas perdas?

\section{Metodologia}

Conhecendo a instituição

A instituição pesquisada é uma organização não-governamental italiana, de caráter filantrópico, vinculada à Igreja Católica, que vem funcionando desde 1994, na cidade de Porto Velho/RO.

Na época da pesquisa, realizada em 2003, oferecia atendimento fisioterápico, fonoaudiológico, psicológico, serviço social e cuidados básicos de higiene a crianças, adolescentes e adultos com diagnóstico de paralisia cerebral, com ou sem deficiência mental.

Para desenvolver esse atendimento, contava com: uma fisioterapeuta, uma fonoaudióloga, quatro monitoras, com formação em ensino médio, responsáveis pelos cuidados básicos de higiene, alimentação e estimulação aos alunos ali atendidos, uma assistente social, que exercia, também, a função de diretora da instituição, e um motorista, contratados pela instituição. Havia, também, dois estagiários do curso de Psicologia da Universidade Federal de Rondônia, na época da realização deste estudo, e voluntários (pais de pacientes ou pessoas da comunidade em geral) que auxiliavam no serviço de limpeza e de cozinha.

A instituição atendia trinta e uma pessoas em regime de externato e sete crianças em sistema residencial, que permaneciam na instituição de segunda a sábado, quando eram levados para a casa de seus familiares. Essa última modalidade de regime de atendimento se devia à carência socioeconômica dessas famílias.

\section{Participantes}

Foram convidados a participar da pesquisa os funcionários contratados pela instituição e os estagiários de Psicologia, sendo agendada uma data para a realização da entrevista, conforme a disponibilidade de cada um. Nove funcionários aceitaram colaborar com este estudo e assinaram o Termo de Consentimento Livre e Esclarecido, conforme as normas de ética em pesquisa contidas na Resolução $n^{\circ}$ 196, do Conselho Nacional de Saúde. Nesse sentido, os nomes aqui apresentados são todos fictícios. Somente a fisioterapeuta e um estagiário não puderam participar, devido à falta de disponibilidade de tempo.

A idade dos participantes variou de trinta a cinqüenta anos. Apenas o motorista era do sexo masculino. Cinco funcionários trabalhavam na instituição há mais de quatro anos, e quatro há menos de um ano. Todos disseram serem católicos, tendo a fonoaudióloga informado seguir, além do catolicismo, o espiritismo.

\section{Abordagem metodológica}

Foi utilizada uma pesquisa qualitativa de estudo de caso, por meio de entrevista semiestruturada gravada em áudio, com cada participante, separadamente, contendo perguntas referentes à temática da morte, que abordavam: como a instituição lida com a morte no seu cotidiano, se tiveram algumas informações sobre essa temática e como gostariam de serem preparados para lidar com a morte.

Para a análise dos dados, efetuou-se o registro ampliado das transcrições das entrevistas, com 
a organização dos dados, num sistema de codificação de categorias descritivas, em que se buscou o material manifesto e o latente presentes nas mensagens (Biasoli Alves; Dias da Silva, 1992; Chizzotti, 1998; Lüdke; André, 1986; Martins, 1999).

\section{Analisando os dados}

\section{O medo da morte}

Falar sobre a morte implica lidar com sentimentos de tristeza, pela constatação da nossa finitude e do medo do desconhecido. Nesta pesquisa, antes mesmo de iniciar a entrevista, percebemos que, em geral, os entrevistados se mostraram, inicialmente, pouco à vontade para falarem sobre a morte, principalmente as monitoras.

O medo da morte, em nossa pesquisa, em concordância com os estudos de Cassorla (1998) e Kovács (2002), também foi associado à:

fragilidade frente à nossa finitude: “...eu acho que é.é o grande medo que se tem quando se fala disso, é.é.é.é.é é sair da nossa fragilidade..." (assistente social).

- inconformismo com a nossa terminalidade: “...Pra mim é uma coisa, morreu acabou, né, eu não aceito, eu tenho medo, eu tenho medo... Aí acabou, não tem mais nada... eu não aceito...” (monitora B).

interrupção de nossos planos futuros: “... que acabamos não valorizando o dia a dia, do que a gente faz, a qualidade da nossa, da nossa vida, né, a gente pensa muito é.é, sempre muito projeto pró futuro, no que amanhã eu vou fazer amanhã, mas se se esquece de hoje, né!” (assistente social).

separação de pessoas queridas: “...eu, eu fico imaginando, assim, quando a minha mãe chegar a partir, eu vou ter tanto tempo longe dela, assim, ... que eи acho, assim, que eи não me imagino..." (monitora A).

Os medos aqui relatados relacionam-se ao medo da própria extinção e da interrupção de sonhos para o futuro, podendo gerar, na pessoa, sentimentos de impotência por não se poder evitar a morte. O medo da extinção de um ente querido também foi relatado, podendo contribuir para a vivência de sentimentos de abandono e inconformismo (Kastenbaum, 1983, citado em Kovács, 1992). Mas não podemos nos esquecer de que o medo da morte verificado nessas falas é um tipo de resposta comum e universal frente ao desconhecido, sendo, segundo Kovács (1992), vital para que possamos superar nossos instintos destrutivos, desde que esse medo não se torne doentio. Para a autora, as possíveis conseqüências desse medo patológico seriam a depressão e a paralisação dessa pessoa diante da vida, com falta de ação no seu dia a dia. O que chamou mais a atenção é que o medo da morte é tanto que, na fala da assistente social, pudemos observar a sua dificuldade em verbalizar a palavra "morte", referindo-se a ela como "quando se fala disso"! Tal dificuldade pode estar associada ao medo de contágio da morte, no sentido de que, quando falamos a palavra "morte", estaríamos chamando a morte para nós e, assim, talvez fôssemos os próximos a morrer, como discutido por Cassorla, (1998).

\section{Falando sobre a perda de familiares}

Embora o enfoque da nossa pesquisa seja sobre a morte na instituição, em geral, os entrevistados traziam, em suas falas, conteúdos relacionados a perdas na família, vivenciando sentimentos de tristeza e de revolta por essa perda:

“...meu pai morreu tem 9 anos, assim, eu nunca superei a morte dele, não, tanto que
"...Pra mimé uma coisa, morreu acabou, né, eu não aceito, eu tenho medo, eu tenho medo... Aí acabou, não tem mais nada.. eu não aceito..."

monitora B 
às vezes eu sonho com ele, eu choro, dia dos pais eu sinto muita falta... se meu pai tivesse vivo, muitas coisas comigo não teria acontecido, ...." (monitora D).

Nesse relato, podemos verificar que o luto, apesar de a perda ter acontecido há nove anos, não foi bem elaborado, existindo, ainda, uma busca pela pessoa perdida, configurandose como a segunda fase do luto, a fase de anseio, explicitada por Bowlby (1985), na qual o enlutado vivencia sentimentos de raiva por não conseguir reestabelecer o elo perdido. Podemos pensar que essa monitora talvez não tenha vivenciado o sentimento de perda do pai, não externalizando a sua dor, o que, para Cassorla (1998), é fundamental para que a pessoa possa retomar a sua vida, mantendo a lembrança do ente perdido com carinho. irmã, ( ) eu não ia no cemitério... porque é uma coisa que eu não gosto de fazer (] não to me esquecendo (dela)

() Em qualquer Iugar eu vou, ela está comigo, é a minha maneira de cultuar ela..."

assistente social
Já outra entrevistada, ao trazer conteúdos relacionados à morte de familiares, demonstra ter elaborado bem o seu luto:

“... quando faleceu a minha irmã, ( ) eu não ia no cemitério ... porque é uma coisa que eu não gosto de fazer ( ) não to me esquecendo (dela) ( ) Em qualquer lugar eu vou, ela está comigo, é a minha maneira de cultuar ela...” (assistente social).

Segundo ela, para lembrar da irmã, não é necessário visitar o cemitério; a lembrança está viva dentro dela, indicando a finalização do processo de luto ao sentir a presença interna da irmã em paz; desse modo, atinge a última fase do luto, a fase de maior ou menor reorganização que, de acordo com Bowlby (1985), acontece quando o enlutado aceita que a perda é permanente, reconstruindo, assim, a sua vida em um ambiente harmônico, que lhe possibilita desenvolver novas amizades (Kovács, 1992).

\section{A morte invertida}

A necessidade de a morte ter que passar despercebida, característica do século XX, apontada por Áries (1990), para que a rotina volte ao normal (Cassorla, 1998), a fim de que não entremos em contato com a possibilidade de nossa finitude, vivenciando, assim, sentimentos que geram grande ansiedade, também foi verificada em nossa pesquisa, apesar de os entrevistados verbalizarem que a morte é um "processo natural":

"É de tentar ter uma postura mais natural possível, porque são crianças como qualquer um, qualquer ser humano, né, é.é.é que possa é.é um dia, vão morrer, né!” （motorista).

O significado de "processo natural" aqui atribuído seria no sentido de que a equipe não pôde vivenciar o sentimento de tristeza pela perda de um dos pacientes ocorrida recentemente, tendo que ocultar o seu luto, para que as atividades da instituição não sofressem alterações:

“Pra nós aqui é.é.é.é.é.é ... como é que se diz, é.é.é, a gente nãooooo ... pra gente não ficar muito triste, né, com aquela perda, porque a gente vai sentir muito, né, vai sentir... aquela perda, a gente tem queee ir em frente, né, continuar o trabalho da gente" (monitora C).

“... eu acho que é assim, não é preparado pra aceitar a morte, mas preparado, ter uma estrutura suficiente psicológica emocional, pra você... não deixar transparecer, é.é.é.é, pra você ser o espelho de si mesmo, prá família que tá perdendo aquele ente querido...” (motorista).

Podemos, assim, observar a existência de uma orientação dada pela instituição, para que os sentimentos frente à perda de um paciente sejam abafados. Mas, como Kovács (2002) e Kübler-Ross (1996; 1998) ressaltam, a camuflagem desses sentimentos poderá dificultar o processo do luto, podendo contribuir para o desenvolvimento de depressão ou desencadear o surgimento de doenças em decorrência da baixa imunidade 
do sistema imunológico (Cassorla, 1998) bem como possibilitar um vínculo menos afetivo entre o profissional e o paciente.

De acordo com Stedefor (1986), a relação pouco afetiva que o profissional de saúde estabelece com seu paciente poderia estar associada ao seu medo de vir a perder o paciente para a morte, sentindo-se desamparado e impotente ao entrar em contato com a finitude de sua vida.

A morte recente, por pneumonia, da paciente Maria, com três anos de idade, que tinha paralisia cerebral com bom prognóstico de desenvolvimento, ainda é lembrada com muita tristeza pelos entrevistados, sendo possível identificar algumas das fases do processo de luto descritas por Bowlby (1985):

fase de entorpecimento: “... no dia que... que a Maria chegou a falecer, eu estava aqui pela manhã,... foi quando o telefone tocou, eraaa a mãe dela... é assim, foi um momentooo difícil, né...” (estagiária de Psicologia).

"Minha aluna... então foi uma coisa assim,... eu cheguei à tarde e a Marta me chamou, quando ela me disse aquilo lá, meu mundo desabou! É uma coisa muito dolorida“ (monitora D).

fase de anseio e busca da pessoa perdida: “... eu entrava no quarto, eu eu tinha a visão que eu tava vendo aquela criança, que eu tava dando banho naquela criança, e até hoje, eu não consigo aceitar, pra mim isso aí não é verdade..." (monitora D).

Essas fases constituem as fases iniciais frente à constatação da perda, mas o importante a se destacar é que os entrevistados necessitaram camuflar o seu pesar, para que os pacientes não percebessem o que tinha acontecido com Maria, tendo, assim, que adiar a vivência desse seu sentimento, o que pode contribuir para o surgimento de doenças:
“... quando a Marta (a diretora da instituição) falou que a Maria tinha morrido, me deu um impacto tão grande, eu tinha que chorar, pra colocar pra fora, aquele meu sentimento... eu cheguei em casa, me deu uma crise de choro, () parecia assim, que tinha partido alguém da minha família..." (monitora D).

A morte invertida na instituição também pode ser percebida quando houve a comunicação indireta do falecimento de Maria aos pais dos pacientes, que só souberam do ocorrido na tradicional missa de final de ano, celebrada em memória de Maria:

"No dia da missa veio os pais, né, a gente falou, nós atééé fizemos a missa em nome dela também, a mãe dela veio, aí os pais escutaram, alguns não sabiam ainda, ficaram assustados, né!” (monitora A).

A reação de susto dos pais frente à comunicação da morte de Maria é um exemplo de como a morte é tratada no século atual, compartilhada sutilmente, quase passando despercebida (Áries, 1990).

Já para os pacientes atendidos pela instituição, foi dito que Maria viajou, ou que estava doente:

“...foi trabalhado a morte dela pras crianças, segundo ela fez uma viagem, né,..., talvez foi embora do Estado, né” $\quad$ (monitora B).

“... A Maria tá no hospital, ela tá doente. Só falam isso, tá doente, tá doente,...” (fonoaudióloga).

Tal forma de comunicação busca esconder a morte, parecendo uma tentativa de negá-la, assim como de negar o sofrimento por essa perda, como foi observado nos trabalhos de Cassorla (1998) e Kovács (2002).

A morte invertida fica clara, também, quando uma das entrevistadas ressalta que o falecimento de Maria trouxera um problema para a instituição, pois uma das pacientes, 
Jaqueline, de 12 anos de idade, com paralisia cerebral sem deficiência mental, percebeu que algo muito grave ocorrera com Maria:

“É.é.é.é só que é assim, a morte da Maria, é.é.é, fez surgir um problema, né, quando aconteceu o fato da Maria, praticamente a Jaqueline, que era muito ligada a ela, ela começou a perceber que tinha acontecido alguma coisa, né, só que ela entendeu só que a menina estava no hospital, aí, é.é, quando isso aconteceu, só de ouvir isso, ela começou a ficar deprimida, ficou na na frente do espelho, não queria falar com ninguém, não queria almoçar” (assistente social).

"... a gente tem que se preparar, é uma coisa que a gente não pode ficar esperando, eles passam pela gente, eles falam, eu vejo hoje uma criança que está alegre, amanhã pode não estar, porque a vida delas é mais cara do que a nossa, nós somos sadios...

hoje você se

apega muito a eles, mas amanhã eles podem não tá... o tempo da vida deles é reduzido"

monitora B
O que chama a atenção nessa fala é que a não-comunicação da morte de Maria para os pacientes parece estar associada a um medo da equipe, com a ocorrência de um possível agravamento do quadro clínico e emocional dos pacientes, como veremos a seguir.

\section{A morte e a deficiência}

Foi possível observar, neste trabalho, uma relação muito forte, feita pela equipe, entre a deficiência do paciente e o risco de ele vir a óbito mais cedo, quando comparado com pessoas sem deficiência:

“...Essas crianças são imprevisíveis...certo, então pode ser, pode ser queee uma delas vive 10,15, 20 anos, pode ser que amanhã uma delas... certo” (motorista).

“... a gente tem que se preparar, é uma coisa que a gente não pode ficar esperando, eles passam pela gente, eles falam, eu vejo hoje uma criança que está alegre, amanhã pode não estar, porque a vida delas é mais cara do que a nossa, nós somos sadios... hoje você se apega muito a eles, mas amanhã eles podem não tá... o tempo da vida deles é reduzido" (monitora B).

Essa comparação pode levar a equipe a estabelecer uma relação profissional-paciente superprotetora, por sentir pena da brevidade da vida dessa pessoa, como também uma relação pouco afetiva, numa tentativa de não se envolver emocionalmente com o paciente, para não vir a sofrer quando este falecer.

Uma outra associação feita foi entre a deficiência, a comunicação da morte de Maria ou de qualquer outra pessoa, e uma possível regressão, ou até mesmo ao agravamento de sua deficiência.

Reações como isolamento, choro e desespero são percebidas pelos entrevistados como uma expressão de regressão ou agravamento da deficiência, e não como reações normais frente à perda de um amigo:

“Com as crianças... porque é assim, eles tendem, assim, a se isolar, eles sempre se isolam, chora, tem assim, aquele momento, assim, de desespero, né,... aí também, é preferível, também, não falar, a gente não comenta com as crianças” (monitora D).

“...A a princípio porque por, por, ser uma, umas crianças excepcionais, então são muito delicadas.. então você nunca chega assim, ela morreu...pode causar um transtorno na na mente da da criança!” (motorista).

"Aline dormia com esse irmão, com quem ela dormia, né, é.é.é, com que faleceu, aí a gente se, é.é.é, ajudou ela a a superar essa fase de luto, né, porque ela não expressava, mas chorava, à noite ela chorava, ficou muito deprimida naquela época, né, é.é, não queria mais comer, ficou numa fase... regrediu muito” (monitora A).

A associação feita entre a deficiência e a possível morte precoce do paciente e entre a deficiência e a comunicação da morte de um ente querido, com a possibilidade de regressão ou agravamento do caso clínico ou emocional do paciente, parece estar vinculada à forma como a clientela atendida é percebida dentro 
da instituição, em que o foco parece estar na deficiência, e não na pessoa.

Essa forma de perceber a pessoa com deficiência é comum em nossa sociedade e leva a atitudes preconceituosas, como é discutido nos trabalhos de Amaral (1995) e Vash (1988), por se depreciar o valor da pessoa e ressaltar a sua deficiência. De acordo com essas autoras, quando um indivíduo possui uma deficiência, aquilo que o torna diferente é o foco das relações, ficando a pessoa em segundo plano. Isso acontece porque, em nossa sociedade, é cultuado o belo, o normal. Nesse sentido, a nossa sociedade tende a segregar as pessoas com deficiência, principalmente quando essa deficiência é visível e bem limitante, como no caso dos pacientes com paralisia cerebral, atendidos na instituição de nossa pesquisa, que necessitam da cadeira de rodas ou de ajuda para sua higiene pessoal ou alimentação.

Dessa maneira, negamos a participação mais efetiva da pessoa com deficiência na sociedade, chegando a ponto, inclusive, de omitir informações importantes, que contribuirão para o seu amadurecimento como pessoa, como, por exemplo, a nãocomunicação do falecimento de um ente querido.

O foco na deficiência levou a instituição a mudar a versão sobre a morte de Maria, para que Jaqueline não viesse a ter uma possível crise convulsiva:

“Aí a Jaqueline teve uma reação deeee isolamento, não queria almoçar, ficou triste, começou a chorar, aí eu tive que mudar a versão né, por causa daquela reação dela, fiquei com medo... dela viesse passar o dia todo, desse alguma é.é.é, algumaaa crise” (monitora A).

Nessa fala, podemos verificar que Jaqueline percebeu, pela reação da equipe, que Maria tinha morrido, vindo a apresentar uma reação imediata de choque pela perda da amiga, isolando-se, não querendo mais almoçar, expressando a sua tristeza e a vivência da fase inicial do luto: a fase de entorpecimento, importante para a elaboração do luto (Bowlby, 1985).

Os profissionais, no entanto, parecem não ter identificado a reação dessa forma, e sim, como reação associada à deficiência, que poderia vir a desencadear convulsões e a agravar o quadro de paralisia cerebral da adolescente.

A morte faz parte do desenvolvimento humano, e nós vivenciamos perdas desde a mais tenra idade, sendo, portanto, importante compartilhar com Jaqueline, assim como com os demais pacientes, a morte de Maria, para que eles pudessem expressar o seu sentimento de pesar e o seu luto (Kovács, 2002), mesmo tendo algum tipo de deficiência. Não podemos afirmar que a morte seja um agente complicador para a deficiência.

O que parece acontecer na instituição estudada, sendo muito comum em locais onde a clientela atendida é composta praticamente por crianças, é o adulto não saber como comunicar a morte, talvez por achar que elas sejam muito pequeninas para sofrerem, principalmente tendo algum tipo de deficiência.

Uma das entrevistadas disse que sabia como falar com os pacientes sobre a morte de Maria, comentando que, nos casos mais comprometidos, o toque permitiria a eles a compreensão de que a coleginha falecera:

"Ai... esses aqui eu acho que a gente vai ter que trabalhar com toque, Iracema, porque assim,..., eu sou extremamente convencida que com as crianças que não fala, a nossa única maneira de nos comunicar é o toque. Aí eu acredito, finalmente que, com o toque, a gente pode passar tudo o que nós queremos, até essas coisas, eu consigo” (assistente social). 
"... Eu penso que não tem essa questão de preparação... é.é.é.é, quando nos deparamos com uma situação desta, eu acho que, assim, a religião pode cooperar pra você dar apoio, o apoio nesse momento, mas preparar, preparar para o momento, nãooo tem"

monitora B
Essa fala mostra que existe um caminho para comunicar a má notícia, mas é interessante notar a dificuldade em se verbalizar a palavra “morte” que, acima, é expressa como "essas coisas”, o que, segundo Cassorla (1998), é freqüente entre as pessoas que temem a morte, que não aceitam o fato de que não viveremos para sempre e de que a nossa vida um dia terá um fim.

\section{Preparação para lidar com a morte}

Em geral, os participantes desta pesquisa acreditam que seja difícil ser ou estar preparado para lidar com a morte, pelo fato de eles não a aceitarem:

"Eu acho que é assim, ninguém nunca, por mais, é.é, seminários, cursos, nunca vai tá preparado, assim, pra morte, até mesmo porqueee a gente é.é... tem muitas pessoas que a gente gosta muito mesmo, né, num caso assim, eu acho que a gente nunca supera...eu acho queee mais ou menos, pode amenizar, né, a gente saber que vai acontecer, tudo,... pode até amenizar mais...” (monitora A).

"Eu acho que a morte, a gente por mais treinamento que a gente faça, é.é.é.é.é... tenha cursos, grupos, isso é uma coisa que a gente, eu, Iracema, pelo menos, nunca vou tá preparada pra isso, porque é uma coisa muito difícil...” (monitora D).

Alguns entrevistados postularam que a religião talvez ajudasse a lidar melhor com a morte, mas não ajudaria na preparação para a mesma:

“... Eu penso que não tem essa questão de preparação... é.é.é.é, quando nos deparamos com uma situação desta, eu acho que, assim, a religião pode cooperar pra você dar apoio, o apoio nesse momento, mas preparar, preparar para o momento, nãooo tem” (monitora B).
Esse receio, talvez possa estar relacionado com a falta de informações sobre a morte, como também pelo fato de ter ocorrido recentemente o falecimento inesperado de Maria. Essa perda repentina parece ter afetado muito os funcionários da instituição, que ainda se encontravam em processo de luto.

Fatores como a morte repentina de um ente querido e a idade do falecido são identificados por Bromberg (1996) e Kovács (1992) como possíveis complicadores para a aceitação da morte, podendo, inclusive, dificultar o processo de luto. Para as autoras, imaginamos que a morte só ocorrerá quando alguém se encontrar gravemente enfermo ou quando tiver uma idade avançada, visto acreditarmos que a criança, por se encontrar em tenra idade, ainda viverá bastante, dificultando, dessa forma, a aceitação da perda.

Com relação à maneira como gostariam de serem trabalhados para lidarem com a morte e o morrer na instituição, verbalizaram que a realização de cursos teóricos e dinâmicas de grupo sobre essa temática poderia ajudá-los a enfrentar melhor a morte:

“Eu acho, Iracema, o primeiro trabalho o trabalho pessoal, a experiência de cada um que cada um teve com a morte né, éé... Eu acho que primeiro a pessoa tem que conhecer isso né, reconhecer isso, e portanto, eu acho que o primeiro trabalho psicológico de trabalho é.é.é pessoal, de autoconhecimento, depois um trabalho teórico né, porque os dois eu acho que complementa, isso eu acho que podeeee servir” (assistente social).

\section{Considerações finais}

Este trabalho oportunizou identificar os tabus relacionados à morte, comum nos estudos sobre a morte e o morrer. A contribuição desta pesquisa estaria no fato de a mesma retratar como os profissionais que atendem pessoas com deficiência lidam com a morte. 
Nesse sentido, o que chama a atenção é a relação feita pela equipe entre deficiência de seus pacientes e a sua expectativa frente a uma possibilidade maior de virem a falecer mais precocemente, bem como a crença de que a comunicação sobre a morte de um ente querido contribuiria para uma possível regressão ou agravamento do quadro da deficiência do paciente.

Tais relações parecem estar relacionadas com o foco da atenção na deficiência e não na pessoa, contribuindo, assim, para a nãocomunicação da morte para os pacientes, devido ao estigma da deficiência. Essa falta de informação poderá trazer sérias conseqüências de saúde física e/ou emocional para a equipe, que necessita sufocar seus sentimentos de pesar, como também para os pacientes, que percebem que algo aconteceu, mas não sabem o porquê. A relação de confiança entre os pacientes e a equipe poderá vir a sofrer um rompimento brusco, quando os pacientes souberem, por meio de outras pessoas, das mortes escondidas, como por exemplo, do falecimento de Maria.

Assim, percebe-se a necessidade de se realizar um trabalho de intervenção na instituição, por meio da execução de um curso sobre a morte e o morrer, para que possam lidar melhor com essa temática no seu cotidiano e nas suas relações com os pacientes com deficiência.

Iracema Neno Cecilio Tada, Professora do Departamento de Psicologia da Universidade Federal de Rondônia. Doutora em Psicologia escolar e Desenvolvimento Humano. Departamento de Psicologia, Universidade Federal de Rondônia. Campus. br 364 km 9,5. porto velho Rondônia. 78900-000 Fone: 69.2182.2025. E-mail: iracematada@hotmail.com

Maria Júlia Kovacs

Professora do Instituto de Psicologia da Universidade de São Paulo. Livre-docente. Instituto de Psicologia - Av. Mello Moraes, 1721. Cidade Universitária. São Paulo - São Paulo. 05508-900. Fone: 11.3091.4185 ramal 213. Fax: 11.38138895. E-mail: mjkoarag@usp.br

Recebido 01/12/05 Reformulado 26/07/06 Aprovado 15/08/06

AMARAL, L.A. Conhecendo a Deficiência: em Companhia de Hércules. São Paulo: Robe Editorial, 1995.

ARIÉS, P. O Homem diante da Morte. Rio de Janeiro: Francisco Alves, 1990.

BIASOLIALVES, Z.M.M.; DIASDASILVA, M.H.G.F.Análise Qualitativa de Dados de Entrevista: uma Proposta. Paidéia, FFCLRP-USP, $n^{\circ}$. 2, fev./jul., 1992.

BOWLBY, J. Perda: Tristeza e Depressão. São Paulo: Martins Fontes, 1985.

BROMBERG, M.H.P.F. Luto: a Morte do Outro em si. In: Bromberg, M.H.P.F.; Kovács, M.J.; Carvalho, M.M.M.J.; Carvalho, V.A. Vida Morte: Laços da Existência. São Paulo: Casa do Psicólogo, 1996.

CASSORLA, R.M.S. Como Lidamos com o Morrer - Reflexões Suscitadas no Apresentar este Livro. In: Cassorla, R.M.S. (org.). Da Morte: Estudos Brasileiros. Campinas: Papirus, 1998.

CHIZZOTTI, A. Pesquisa em Ciências Humanas e Sociais. São Paulo, Cortez, 1998.

KOVÁCS, M.J. Morte e Desenvolvimento Humano. São Paulo: Casa do Psicólogo, 1992.

Pensando a Morte e a Formação de Profissionais de Saúde. In: Cassorla, R. M.S. (org.). Da Morte: Estudos Brasileiros. Campinas: Papirus, 1998.
Educação para a Morte: um Desafio na Formação de Profissionais de Saúde e Educação. São Paulo, 2002. Tese de Livre-Docência. Instituto de Psicologia, Universidade de São Paulo, São Paulo, 2002.

KÜBLER-ROSS, E. Sobre a Morte e o Morrer. São Paulo: Martins Fontes, 1996.

A Roda da Vida. Rio de Janeiro: GMT, 1998.

LÜDKE, M.; ANDRÉ, M.E.D.A. Pesquisa em Educação: Abordagens Qualitativas. São Paulo:EPU, 1986.

MARTINS, J. A Pesquisa Qualitativa. In: Fazenda, Ivani (org.). Metodologia da Pesquisa Educacional. 5a. ed. São Paulo: Cortez, 1999.

STEDEFORD, A. Encarando a Morte: uma Abordagem ao Relacionamento com o Paciente Terminal. Porto Alegre: Artes Médicas, 1986.

TORRES, W.C.; GUEDES, W.G.; TORRES, R.C.; EBERT, T. Algumas Contribuições à Pesquisa sobre a Morte. In: Cassorla, Roosevelt, M.S (org.). Da Morte: Estudos Brasileiros. Campinas: Papirus, 1998.

VASH, C.L. Enfrentando a Deficiência: a Manifestação, a Psicologia, a Reabilitação. São Paulo: Pioneira: EDUSP, 1988. 